\title{
The 11S globulin Sin a 2 from yellow mustard seeds shows lgE cross-reactivity with homologous counterparts from tree nuts and peanut
}

\author{
Sofía Sirvent ${ }^{1}$, Martial Akotenou', Javier Cuesta-Herranz ${ }^{2}$, Andrea Vereda ${ }^{2}$, Rosalía Rodríguez ${ }^{1}$, Mayte Villalba ${ }^{1}$ \\ and Oscar Palomares ${ }^{1 *}$
}

\begin{abstract}
Background: The $11 \mathrm{~S}$ globulin Sin a 2 is a marker to predict severity of symptoms in mustard allergic patients. The potential implication of Sin a 2 in cross-reactivity with tree nuts and peanut has not been investigated so far. In this work, we studied at the IgG and IgE level the involvement of the $11 \mathrm{~S}$ globulin Sin a 2 in cross-reactivity among mustard, tree nuts and peanut.

Methods: Eleven well-characterized mustard-allergic patients sensitized to $\operatorname{Sin}$ a 2 were included in the study. A specific anti-Sin a 2 serum was obtained in rabbit. Skin prick tests (SPT), enzyme-linked immunosorbent assay (ELISA), immunoblotting and IgG or IgE-inhibition immunoblotting experiments using purified $\operatorname{Sin}$ a 2, Sin a 1, Sin a 3, mustard, almond, hazelnut, pistachio, walnut or peanut extracts were performed.

Results: The rabbit anti-Sin a 2 serum showed high affinity and specificity to Sin a 2, which allowed us to demonstrate that $\operatorname{Sin}$ a 2 shares $\lg \mathrm{G}$ epitopes with allergenic $11 \mathrm{~S}$ globulins from tree nuts (almond, hazelnut, pistachio and walnut) but not from peanut. All the patients included in the study had positive skin prick test to tree nuts and/or peanut and we subdivided them into two different groups according to their clinical symptoms after ingestion of such allergenic sources. We showed that $11 \mathrm{~S}$ globulins contain conserved IgE epitopes involved in cross-reactivity among mustard, tree nuts and peanut as well as species-specific lgE epitopes.

Conclusions: The allergenic 11S globulin Sin a 2 from mustard is involved in cross-reactivity at the lgE level with tree nuts and peanut. Although the clinical relevance of the cross-reactive IgE epitopes present in $11 \mathrm{~S}$ globulins needs to be investigated in further detail, our results contribute to improve the diagnosis and management of mustard allergic patients sensitized to Sin a 2.
\end{abstract}

Keywords: Food allergy, Mustard allergy, Tree nut allergy, Peanut allergy, Cross-reactivity, 115 globulins, Sin a 2, $\lg \mathrm{G} / \mathrm{lgE}$ epitopes

\section{Background}

IgE-mediated food allergy is an important worldwide health problem of increasing prevalence affecting up to $2-10 \%$ of the population [1,2]. More than 170 foods have been reported to induce allergic responses being peanuts, tree nuts, eggs, milk, fish, shellfish, wheat and soy responsible for the vast majority of reactions. Mustard is one of the most frequent spices causing IgE-mediated

\footnotetext{
* Correspondence: oscar.palomares@quim.ucm.es

${ }^{1}$ Department of Biochemistry and Molecular Biology, School of Chemistry,

Complutense University of Madrid, Madrid 28040, Spain

Full list of author information is available at the end of the article
}

food allergy, and together with celery, sesame, lupine and shellfish is considered among the most significant allergenic sources in European countries [3]. The ingestion of mustard seed flour or manufactured foods containing this spice has been frequently associated with the development of severe symptoms such as generalized urticaria, angioedema or anaphylaxis in hypersensitive patients [4-7]. Mustard is worldwide consumed in home-made meals and added as a hidden condiment in many sauces, salad dressings or manufactured and processed products, which makes difficult to avoid the ingestion of this spice and increases the risk of suffering

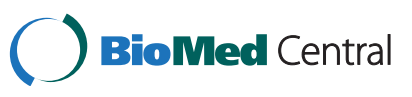


unexpected life-threatening reactions [8]. Therefore, mustard content must be declared according to the European Union directive for food labelling [9]. Yellow mustard (Sinapis alba L.) is commonly used in Europe whereas oriental mustard (Brassica juncea) is the spice used in United States and Asia.

Four allergens from yellow mustard seeds have been identified, purified and characterized so far: i) $2 \mathrm{~S}$ albumin Sin a $1(14 \mathrm{kDa})[10,11]$; ii) $11 \mathrm{~S}$ globulin $\operatorname{Sin}$ a 2 $(51 \mathrm{kDa})[12,13]$; iii) LTP Sin a $3(12 \mathrm{kDa})$ [14]; and iv) profilin Sin a $4(13-14 \mathrm{kDa})$ [14]. Sin a 1 and Sin a 3 but not Sin a 4 might act as genuine food allergens able to reach the gut immune system due to their high structural and immunological stability [15]. The capacity of Sin a 2 to act as primary sensitizer at the intestinal mucosa has not been investigated so far. We also demonstrated that $\operatorname{Sin}$ a 1 is a diagnostic marker for sensitization to mustard, Sin a 2 is a marker to predict severity of symptoms, and Sin a 3 and Sin a 4 are allergens associated with sensitization to other plant-derived foods from the Rosaceae family and pollens [16]. It has been reported that more than $50 \%$ of patients allergic to mustard present hypersensitivity to other different vegetable foods, mainly nuts and legumes, but whether this is due to cross reactivity and the allergens involved in such processes is an aspect that needs further investigations [16-18]. At this regard, $11 \mathrm{~S}$ globulins might represent good candidates. Allergenic members of this protein family have been characterized from almond (Pru du 6) [19], hazelnut (Cor a 9) [20,21], peanut (Ara h 3) [22], walnut (Jug r 4) [23], pistachio (Pis v 2) [24], soybean (glycinins G1-G2) [25], Brazil nut (Ber e 2) [26], cashew nut (Ana o 2) [27], sesame seeds (Ses i 6) [28] or pecan (Car i 4) [29]. Some studies have previously shown that $11 \mathrm{~S}$ globulins are involved in crossreactivity between coconut and walnut [30], among buckwheat, poppy and hazelnut [31] or between peanut and other different seeds spices [32]. In addition, two more detailed studies at the molecular level based on the three-dimensional (3D) structure of the allergens and identification of IgE-binding sites suggested that Jug r 4 shows cross-reactivity with Car i 4 [29] or with Cor a 9 and other 11S globulins [33,34]. Despite these reported data, there is still little evidence of IgE-cross reactivity involving $11 \mathrm{~S}$ globulins, a family of proteins with an overall sequence identity under $40 \%$.

In the present study, we sought to investigate the potential implication of the 11S globulin Sin a 2 in crossreactivity involving mustard, tree nuts and peanut. Our results show that the allergenic $11 \mathrm{~S}$ globulin $\operatorname{Sin}$ a 2 shares IgG epitopes with homologous counterparts from almond, hazelnut, pistachio and walnut but not from peanut and that Sin a 2 is involved in IgE crossreactivity with tree nuts and peanut.

\section{Methods}

\section{Patients allergic to mustard}

The patients included in this study were a subgroup of well-characterized patients allergic to mustard [16] who presented specific IgE antibodies against purified $11 \mathrm{~S}$ globulin Sin a 2 as determined by both enzyme-linked immunosorbent assay (ELISA) and skin prick test (SPT). Allergy to mustard was diagnosed as previously described [35]. During the patient consultation a questionnaire gathering clinical information was filled out by an allergist. Clinical features of the patients are shown in Table 1. Although not all of the patients were allergic to tree nuts and/or peanut, all of them had positive SPT to at least one of these allergenic sources. We pooled patient's sera into two different groups: i) Group 1, patients without clinical symptoms to tree nuts and/or peanut; ii) Group 2, patients with clinical symptoms to some of these allergenic sources (Table 1, Table 2). Serum samples from all the patients were collected and storage at $-20^{\circ} \mathrm{C}$ until used. Sera from a non-atopic subject and from an olive pollen-allergic patient were used as controls. The study was approved by the Fundación Jiménez Díaz Ethic Committee (Madrid), and written informed consent was obtained from all subjects.

\section{Yellow mustard seeds extract, purified Sin a 2 and rabbit} anti-Sin a 2 serum

Yellow mustard seeds, almond, hazelnut, pistachio, walnut and roasted peanut protein extracts were obtained as previously described for yellow mustard seeds [12]. The allergenic 11S globulin Sin a 2 was purified from yellow mustard seeds extract as described [12].

The specific anti-Sin a 2 serum was prepared by immunizing a New Zealand white rabbit with purified Sin a 2 by weekly injection of the protein in complete Freund's adjuvant. After 21 days of treatment the serum was obtained by centrifugation of the blood.

\section{Skin-prick tests}

SPT were performed in all patients according to standard procedures [36]. The panel of commercial food extracts included peach, chestnut, soy, sunflower seed, almond, hazelnut, peanut, walnut, pine nut, pistachio, chickpea, lentil and bean. SPT with kiwi and apple were performed by the prick-prick method as described [37]. SPT with home-made mustard (Sinapis alba L.) extract $(50 \mu \mathrm{g} / \mathrm{ml})$ and with purified natural Sin a $2(10 \mu \mathrm{g} / \mathrm{ml})$ were performed. Histamine dihydrochloride $(10 \mathrm{mg} / \mathrm{ml})$ and physiologic saline solutions were used as the positive and negative controls, respectively. A wheal area $<7 \mathrm{~mm}^{2}$ was considered as negative. We included almond as a nut (instead of a Rosaceae fruit), and considered peanut separately. 
Table 1 Clinical characteristics of patients with mustard allergy sensitized to Sin a 2

\begin{tabular}{|c|c|c|c|c|c|c|c|c|c|c|c|c|}
\hline \multirow[t]{2}{*}{ Patient No } & & \multirow{2}{*}{$\begin{array}{l}\text { Sex/ } \\
\text { age } \\
\text { (y) }\end{array}$} & \multirow[t]{2}{*}{ Mustard Symptoms } & \multicolumn{2}{|c|}{ SPT* $^{*}$} & \multirow{2}{*}{$\begin{array}{l}\text { Other } \\
\text { food } \\
\text { allergies }\end{array}$} & \multicolumn{5}{|c|}{ SPT* } & \multirow{2}{*}{$\begin{array}{l}\text { Tree nuts/ } \\
\text { peanut } \\
\text { Symptoms }\end{array}$} \\
\hline & & & & Mustard & $\operatorname{Sin}$ a 2 & & Almond & Hazelnut & Pistachio & Walnut & $\overline{\text { Peanut }}$ & \\
\hline \multirow[t]{5}{*}{ GROUP 1} & 1 & $F / 51$ & $\mathrm{OAS}, \mathrm{U}, \mathrm{AE}, \mathrm{D}$ & 221 & 69 & no & 16 & 19 & Neg & 9 & Neg & - \\
\hline & 2 & $M / 50$ & $O A S, A E, D$ & 97 & 52 & no & Neg & Neg & Neg & 15 & Neg & - \\
\hline & 3 & $M / 29$ & OAS, U, RC, D & 87 & 37 & $r, l, m$ & Neg & 30 & 22 & 36 & 29 & - \\
\hline & 4 & $M / 36$ & OAS, U & 137 & 139 & $\mathrm{r}, \mathrm{m}$ & 20 & 10 & 20 & 18 & 17 & - \\
\hline & 5 & $\mathrm{~F} / 54$ & $\mathrm{OAS}, \mathrm{U}, \mathrm{TT}, \mathrm{A}, \mathrm{RC}, \mathrm{D}$ & 101 & 35 & $r, k$ & Neg & Neg & Neg & 18 & 39 & - \\
\hline \multirow[t]{6}{*}{ GROUP 2} & 6 & $F / 30$ & OAS,CU,TT, D & 119 & 46 & $k, n$ & 15 & Neg & Neg & 9 & 7 & OAS \\
\hline & 7 & $\mathrm{M} / 30$ & $\mathrm{OAS}, \mathrm{U}, \mathrm{AE}, \mathrm{T}, \mathrm{A}, \mathrm{RC}, \mathrm{D}$ & 103 & 50 & $r, n, p$ & Neg & Neg & 14 & Neg & Neg & OAS \\
\hline & 8 & $\mathrm{M} / 30$ & $\mathrm{OAS}, \mathrm{U}, \mathrm{AE}, \mathrm{T}, \mathrm{A}, \mathrm{RC}$ & 171 & 83 & $n$ & 21 & 14 & 11 & 8 & 17 & $\mathrm{OAS}, \mathrm{RC}, \mathrm{A}$ \\
\hline & 9 & $\mathrm{M} / 30$ & $\mathrm{OAS}, \mathrm{AE}, \mathrm{A}, \mathrm{RC}$ & 169 & 22 & $r, k, n, p, m$ & 21 & 82 & 35 & 124 & 38 & $\mathrm{OAS}, \mathrm{AE}, \mathrm{TT}$ \\
\hline & 10 & $F / 31$ & $\mathrm{OAS}, \mathrm{AE}, \mathrm{CU}, \mathrm{TT}, \mathrm{A}$ & 55 & 25 & $r, k, n, p, m$ & 23 & 57 & 40 & 59 & 64 & $\mathrm{OAS}, \mathrm{AE}, \mathrm{TT}, \mathrm{RC}$ \\
\hline & 11 & $\mathrm{M} / 6$ & OAS, Tा (local) & 73 & 8 & $k, n$ & Neg & 56 & Neg & 54 & Neg & $A E, U$ \\
\hline
\end{tabular}

$M / F$, male/female; $A$, asthma; $A E$, angioedema; $C U$, contact urticaria; $D$, digestive symptoms; $O A S$, oral allergy syndrome; $R C$, rhinoconjuctivitis; $U$, urticaria; $\Pi$, throat tightness; $k$, kiwi; l, legumes; $m$, melon; $n$, nuts (including almond); $p$, peanut; $r$, rosaceae family (excluding almond); Neg, negative $(<0.100$ for ELISA and wheal area $<7 \mathrm{~mm}^{2}$ for SPT).

* Skin prick test: wheal area in $\mathrm{mm}^{2}$.

Group 1: Tolerant to tree nuts and peanut.

Group 2: Symptoms with tree nuts and/or peanut.

\section{Electrophoresis and immunoblotting}

SDS-PAGE was performed in $15 \%$ polyacrylamide gels. Proteins $(0.5 \mu \mathrm{g} /$ lane of purified proteins or $50 \mu \mathrm{g} /$ lane of protein extracts) were visualized by Coomassie Blue or alternatively transferred to nitrocellulose membranes (Amersham, Buckinghamshire, United Kingdom). The protein concentration was determined using the method of bicinchoninic acid (Pierce Chemical Co, Rockford, Ill, USA).

Immunodetection of proteins in membranes was achieved as described [14] by using different pool of sera from patients allergic to mustard, (diluted 1/5), or rabbit

Table 2 Specific IgE to mustard extract and purified mustard allergens by ELISA

\begin{tabular}{ccccccc}
\hline & & \multicolumn{5}{c}{ ELISA Patient No $_{492}$} \\
\cline { 2 - 7 } & & Mustard & Sin a 1 & Sin a 2 & Sin a 3 & Sin a 4 \\
\hline GROUP 1 & 1 & 3.366 & 3.186 & 0.980 & Neg & Neg \\
& 2 & 1.041 & 0.590 & 0.787 & Neg & Neg \\
& 3 & 2.809 & 2.648 & 0.466 & 1.580 & 0.857 \\
& 4 & 3.500 & 3.500 & 2.138 & Neg & Neg \\
& 5 & 0.847 & 0.553 & 0.529 & Neg & Neg \\
\hline GROUP 2 & 6 & 3.477 & 3.532 & 2.138 & Neg & Neg \\
& 7 & 1.327 & 1.153 & 0.119 & Neg & Neg \\
& 8 & 0.934 & 0.920 & 0.166 & Neg & Neg \\
& 9 & 0.856 & 0.643 & 0.162 & 0.117 & Neg \\
& 10 & 0.441 & 0.398 & 0.111 & 1.965 & 0.979 \\
& 11 & 1.508 & 0.738 & 0.216 & Neg & Neg \\
\hline
\end{tabular}

\# Specific lgE determined in ELISA as OD at $492 \mathrm{~nm}$. Neg, negative $(<0.100)$. Group 1: Tolerant to tree nuts and peanut.

Group 2: Symptoms with tree nuts and/or peanut. specific anti-Sin a 2 serum (diluted 1/100000). The binding of human IgE was detected by mouse anti-human IgE antibodies, provided by ALK-Abelló (Madrid, Spain), diluted 1/5000, followed by horseradish peroxidaselabelled goat anti-mouse IgG (diluted 1/5000; Pierce). Reaction to anti-Sin a 2 serum was detected by horseradish peroxidase-labelled goat anti-rabbit IgG (diluted 1/3000; BioRad, Richmond, CA). The signal was developed by using the ECL-Western blotting reagent (Amersham). For the IgG and IgE-inhibition experiments in immunoblotting, the pools of sera (diluted 1/5) or the rabbit anti-Sin a 2 serum (diluted 1/100000) were preadsorbed with $1 \mathrm{mg} / \mathrm{ml}$ of yellow mustard seeds, almond, hazelnut, walnut, pistachio or peanut extracts or with $20 \mu \mathrm{g} / \mathrm{ml}$ of purified Sin a 2 for $2 \mathrm{~h}$ prior to membrane incubation as described [38]. Bovine serum albumin (BSA) was used as negative controls of inhibition. Volummograms of the reactive bands were analysed by scanning densitometry using the computer program Multigauge V3.0.

\section{ELISA experiments}

IgG quantitation was performed by ELISA in microtiter plates (Costar, Corning, NY, USA) coated with $100 \mu \mathrm{l} /$ well of purified $\operatorname{Sin}$ a $2(2 \mu \mathrm{g} / \mathrm{ml})$ or yellow mustard seeds extract $(20 \mu \mathrm{g} / \mathrm{ml})$ [14]. Plates were incubated with increasing dilutions of the rabbit anti-Sin a 2 serum for titration. Then, the plates were incubated with horseradish peroxidase-labelled goat anti-mouse IgG as describe above and peroxidase reaction was developed using fresh enzyme substrate and measuring optical density (OD) at 
$492 \mathrm{~nm}$. Each value was calculated as the mean of 2 determinations after blank subtraction.

For IgG-inhibitions ELISA, after being coated with $100 \mu \mathrm{l}$ of Sin a $2(2 \mu \mathrm{g} / \mathrm{ml})$ or yellow mustard seeds extract $(20 \mu \mathrm{g} / \mathrm{ml})$, the plates were incubated with the rabbit anti-Sin a 2 serum (diluted 1/100000) previously preadsorbed with increasing amounts of $\operatorname{Sin}$ a 2 and mustard extracts as inhibitors for $2 \mathrm{~h}$ [38]. Then, the plates were incubated with horseradish peroxidaselabelled goat anti-mouse IgG and peroxidase reaction developed as described above. The percentage of inhibition was determined according to the formula: \% Inhibition $=\left(1-\left(\mathrm{OD}_{492 \mathrm{~nm}}\right.\right.$ with inhibitor $/ \mathrm{OD}_{492 \mathrm{~nm}}$ without inhibitor)) $\mathrm{x}$ 100. All the determinations were carried out as duplicates.

\section{Sequence alignment and three-dimensional modelling}

Multiple sequence alignments of Sin a 2, Pru du 6, Cor a 9, Pis $\mathrm{v}$ 2, Jug $\mathrm{r} 4$ and Ara $\mathrm{h} 3$ (accession numbers Q2TLW0, E3SH28, Q8W1C2, B7P073, Q2TPW5 and O82580, respectively) were performed with the Clustal Omega program [39]. Amino acid sequences of all 11S globulins are shown without signal peptide. Location of the signal peptide cleavage sites were predicted using SignalP 4.0 Server [40]. The 3D structure of Sin a 2 was modelled by using the services of the Swiss-Model Protein Modelling Server [41] and the structure of the soybean legumin Gly m 6 (PDB code 1od5A) [42] as template. The 3D structure of Ara h 3 correspond to PDB: 3c3v. Graphical processing of the threedimensional structures was accomplished with PDB viewer PyMOL program.

\section{Results and discussion}

Clinical features of mustard-allergic patients sensitized to Sin a 2 suggest that $11 \mathrm{~S}$ globulins might be involved in cross-reactivity with tree nuts and/or peanut

By linking the clinical features of 34 well-characterized patients allergic to mustard with component-resolved approaches we previously showed that $2 \mathrm{~S}$ albumin Sin a 1 is a marker of genuine sensitization to mustard, $11 \mathrm{~S}$ globulin Sin a 2 is associated to severe symptoms after mustard ingestion and LTP Sin a 3 and profilin Sin a 4, two well-known panallergens, are associated with sensitization to other plant-derived foods from the Rosaceae family and pollens [16]. Although more than 50\% of mustard allergic patients are also sensitized to tree nuts and/or peanut, significant clinical associations between sensitization to Sin a 2 and being allergic to other tree nuts or peanut were not found within our cohort of mustard allergic patients [16]. However, considering that recent studies suggested that $11 \mathrm{~S}$ globulins are implicated in cross-reactivity among taxonomically unrelated tree nuts and peanut [30-33] and that different members of this protein family have been reported as relevant allergens [19-24], we investigated at the IgG and IgE level whether the $11 \mathrm{~S}$ globulin Sin a 2 might be implicated in cross-reactivity among mustard, tree nuts and peanut within mustard allergic patients specifically sensitized to Sin a 2. We included in the study the 11 patients allergic to mustard with the general clinical characteristics summarized in Table 1. All patients presented allergic reactions within the first 30 minutes after mustard consumption and the inclusion criteria was based on positive specific IgE to yellow mustard seed extract and Sin a 2 as determined by SPT and ELISA (Tables 1 and 2). In line with our previous data, 10 of the 11 patients sensitized to Sin a 2 developed immediate systemic reactions after the ingestion of mustard and 7 attended the emergency room, where epinephrine was administrated [16]. All the patients included in the study had also positive SPT to tree nuts (almond or hazelnut or pistachio or walnut) or peanut and 6 of them (\# 6, 7, 8, 9, 10 and 11) suffered from symptoms after ingestion of tree nuts ( 3 of them also with peanut, \# 2, 4 and 5). Interestingly, only 3 patients showed positive specific IgE to the previously known cross-reactive mustard allergens Sin a 3 and 2 to Sin a 4 (Table 2), suggesting a potential role of Sin a 2, at least in the observed positive SPT to tree nuts and/or peanut. To further analyse the implication of Sin a 2 in cross-reactivity at the IgG and IgE level and to determine potential clinical relevance within the mustard allergic patients sensitized to $\operatorname{Sin}$ a 2 , we obtained a rabbit anti-Sin a 2 serum and pooled patients' sera into two different groups: i) Group 1, patients with positive SPT to tree nuts and/or peanut extracts without clinical symptoms to these allergenic sources; ii) Group 2, patients with positive SPT to tree nuts and/or peanut extracts with clinical symptoms to some of these allergenic sources (Table 1).

\section{IgG epitopes of the 11S globulin Sin a 2 are present in almond, hazelnut, pistachio and walnut but not in peanut extracts}

Compelling experimental evidence demonstrated that the use of well-defined purified allergens is very useful to improve diagnosis and treatment of allergic diseases $[43,44]$. The availability of purified allergens allows the obtaining of specific polyclonal antibodies in mice or rabbit, which are key tools in the identification of potential cross-reactive homologous allergens in taxonomically related and non-related allergenic sources [14,45]. We employed purified Sin a 2 to raise a rabbit anti-Sin a 2 serum as described in the methods section. The specific anti-Sin a 2 serum was titrated against purified Sin a 2 and yellow mustard seeds extract by ELISA and immunoblotting (Figure $1 \mathrm{~A}$ and $\mathrm{B}$ ). As shown in Figure $1 \mathrm{~A}$, the rabbit anti-Sin a 2 serum displayed equal 


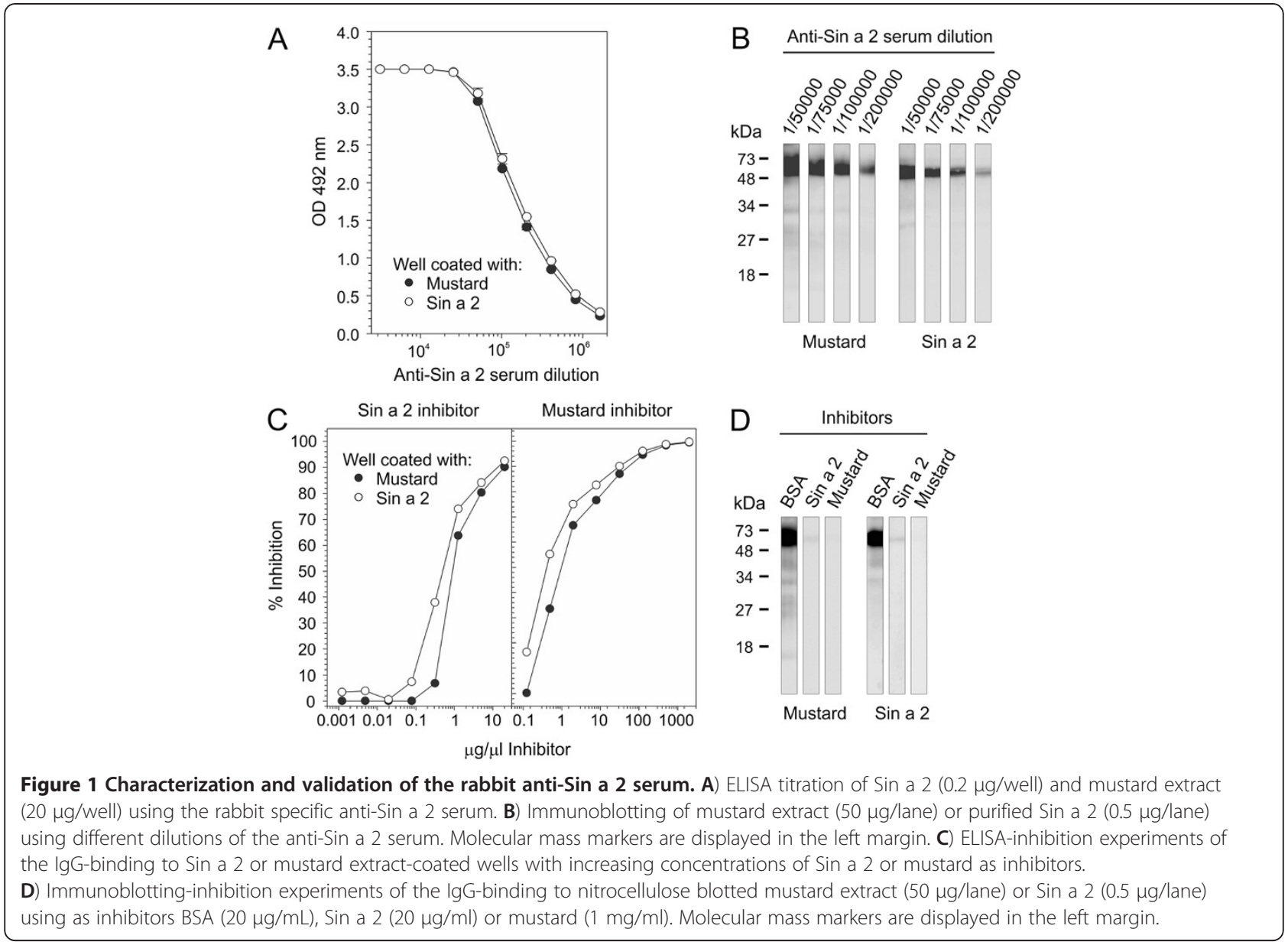

and very high affinity to both purified Sin a 2 and mustard extract, demonstrating that purified Sin a 2 conserved the IgG epitopes and that the employed rabbit anti-Sin a 2 serum is specific to this allergen. The antiSin a 2 serum also recognized the protein band at around $51 \mathrm{kDa}$, corresponding to Sin a 2, in the mustard extract and the purified allergen in a dose-dependent manner in immunoblotting (Figure 1B). When the rabbit anti-Sin a 2 serum was employed at the highest concentration (dilution 1/50000), protein bands at around 30-32 kDa were slightly detected in both cases. These protein bands, which are also recognized by sera from mustard allergic patients, were previously identified as proteolytic fragments of Sin a 2 in mustard extract [13]. To further verify the specificity of the anti-Sin a 2 serum we performed IgG-inhibition experiments in ELISA and immunoblotting (Figure $1 C$ and D). As shown in these figures, both purified Sin a 2 and mustard extract were able to block IgG binding to whole mustard extract or to Sin a 2-coated wells in a similar manner (Figure 1C). Complete inhibition of the binding of the anti-Sin a 2 serum to mustard extract or to purified Sin a 2 was reached when purified Sin a 2 or whole mustard extract were employed as inhibitors (Figure 1D). Collectively, all these data showed that the raised rabbit anti-Sin a 2 serum displays high affinity and specificity for the allergenic $11 \mathrm{~S}$ globulin Sin a 2. Next, we tested the presence of IgG epitopes common to Sin a 2 in tree nut (almond, hazelnut, pistachio and walnut) and peanut extracts (Figure 2). These tree nuts and peanut extracts were selected because they were the most relevant allergenic sources to which the patients included in the study were allergic to or had positive SPT (Table 1). In Figure 2A, the Coomassie Blue staining after SDS-PAGE is displayed to visualize the protein content of the different extracts. The anti-Sin a 2 serum (lanes I) but not the pre-immune one (lanes $\mathrm{P}$ ) reacted with protein bands at around $48-52 \mathrm{kDa}$ in all the tested tree nut extracts. No reaction was detected when peanut extract was assayed. These results demonstrated that the previously described allergenic 11S globulins from almond (Pru du 6),[19] hazelnut (Cor a 9) [20], pistachio (Pis v 2) [24] and walnut (Jug r 4) [23] but not from peanut (Ara h 3) [22] share common IgG epitopes with Sin a 2 . As shown in Figure 3, despite showing quite low percentages of identity (ranging between 28 and 39\%) and similarity 


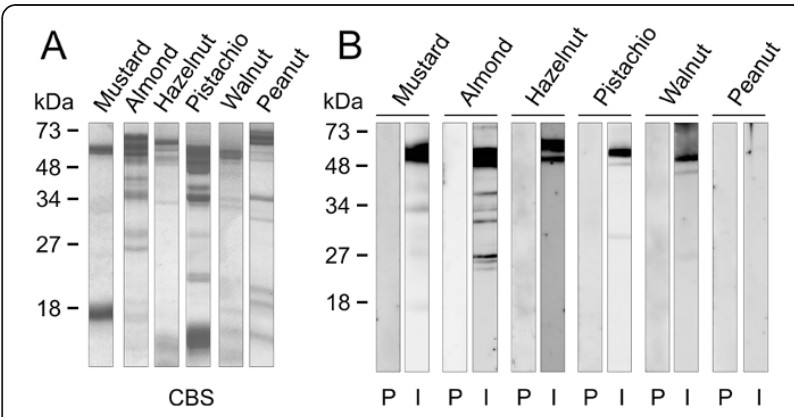

Figure 2 Identification of IgG cross-reactive 11S globulins homologous to Sin a 2 in tree nut extracts. A) SDS-PAGE and Coomassie Blue staining (CBS) of $40 \mu \mathrm{g} / \mathrm{lane}$ of mustard, almond, hazelnut, walnut, pistachio and peanut protein extracts. B) Reactivity of the anti-Sin a 2 serum diluted 1/50000 (lanes I) to mustard, almond, hazelnut, walnut, pistachio and peanut protein extracts (50 $\mathrm{\mu g} / \mathrm{lane}$ ). A pre-immune rabbit serum (lanes P) was used at the same dilution as negative control. Molecular mass markers are displayed in the left margin.

(between 46 and 56\%), the compared $11 \mathrm{~S}$ globulins present regions with conserved amino acid sequences such as for example those encompassing $\mathrm{Gly}^{89}{ }^{8} \mathrm{Asp}^{96}$, His $^{155}$ - Asp $^{165}$ or $\mathrm{Phe}^{420}-\mathrm{Ser}^{436}$ (underlined in Figure 3). Ara $\mathrm{h} 3$ is the $11 \mathrm{~S}$ globulin showing the lowest identity (28\%) and similarity (46\%) with Sin a 2 and significant differences in the amino acid sequences of the above mentioned regions are also observed (Figure 3). Therefore, the presence of IgG binding sites at these regions, which do not completely overlap with the previously identified IgE hot spots (HS), might well justify the lack of reactivity of the anti-Sin a 2 serum against Ara $h 3$. To complement these data, we performed IgG-inhibition experiments in immunoblotting using BSA, purified Sin a 2 or mustard as controls, and almond, hazelnut, pistachio or walnut as potential inhibitors of the IgG binding to purified Sin a 2 (Figure 4A). The reactivity to Sin a 2 of the anti-Sin a 2 serum preadsorbed with purified Sin a 2 or mustard extract was nearly abolished (95 and 99\% of inhibition respectively, quantified by scanning densitometry). When tree nut extracts were employed as inhibitors, an important reduction of the IgG-binding to Sin a 2 was also reached in all the cases. Almond and walnut were the extracts showing the highest inhibitory capacity ( $77 \%$ and $60 \%$ of inhibition, respectively) followed by hazelnut $(53 \%)$ and pistachio $(43 \%)$ as determined by scanning densitometry. Sin a 2 displays a region enriched in Gln and Gly (positions Gly ${ }^{118}-\mathrm{Arg}^{152}$, Figure 3), which is contained exclusively in Pru du 6. If this segment bears IgG binding sites, it might justify the highest percentage of inhibition reached by almond extract. As expected considering that the specific rabbit serum was raised against purified Sin a 2, the IgG binding to almond, hazelnut, pistachio and walnut was completely abolished when purified Sin a 2, mustard or the corresponding tree nut extract were used as inhibitors (Figure 4B). Collectively, all these results firmly demonstrated that Sin a 2 shows cross-reactivity with the allergenic $11 \mathrm{~S}$ globulins from almond, hazelnut, pistachio and walnut at the IgG level, indicating that despite their low percentage of sequence identity they share IgG epitopes likely located in the most conserved regions of the protein family.

\section{IgE cross-reactivity among allergenic $11 \mathrm{~S}$ globulins from}

\section{mustard, tree nuts and peanut}

To gain insight into the potential role of $\operatorname{Sin}$ a 2 in cross-reactivity involving mustard, tree nuts and peanut at the IgE level, we performed IgE-inhibition experiments in immunoblotting using purified Sin a 2 and allergenic protein extracts from mustard, different tree nuts (almond, hazelnut, pistachio and walnut) and peanut. We pooled the patients' sera into two different groups. In the group 1 we included the 5 patients without clinical symptoms to tree nuts and/or peanut at the moment of the study and in the group 2 the 6 patients that were allergic to tree nuts ( 3 of them also to peanut) (Table 1). As shown in Figure 5A, the reactivity to purified Sin a 2 of the pool of sera from group 1 preadsorbed with almond, hazelnut, walnut, pistachio or peanut was inhibited at different level depending on the employed extract. By scanning densitometry we quantified that almond (63\% of inhibition) was the most potent inhibitor followed by walnut, pistachio, peanut and hazelnut (49\%, $34 \%, 32 \%$, and $15 \%$, respectively). Interestingly, the pool of sera from group 1 recognized allergenic $11 \mathrm{~S}$ globulins homologous to Sin a 2 in almond, hazelnut, pistachio, walnut and peanut. The IgE-binding to these proteins was nearly totally abolished when the pool of sera was preadsorbed with purified Sin a 2 except for hazelnut and peanut (Figure 5B), which might be due to cosensitization to species-specific epitopes from $11 \mathrm{~S}$ globulins contained in these allergenic extracts, the existence of different allergenic isoforms or the presence of additional allergens with the same molecular weight in hazelnut and peanut. These results show that for these patients $\operatorname{Sin}$ a 2 is the sensitizing allergen that shares common IgE epitopes with allergenic 11S globulins from the assayed extracts, which could explain why these patients despite of not suffering from clinical symptoms to tree nuts or peanut show in vivo positive SPT to such allergenic sources. To further investigate the potential clinical relevance of $11 \mathrm{~S}$ globulin Sin a 2 in crossreactivity, we performed the same type of experiments using the pool of sera from the mustard allergic patients sensitized to Sin a 2 with clinical symptoms to tree nuts and/or peanut (group 2). As shown in Figure 5C, the IgE-binding to purified Sin a 2 was significantly inhibited 

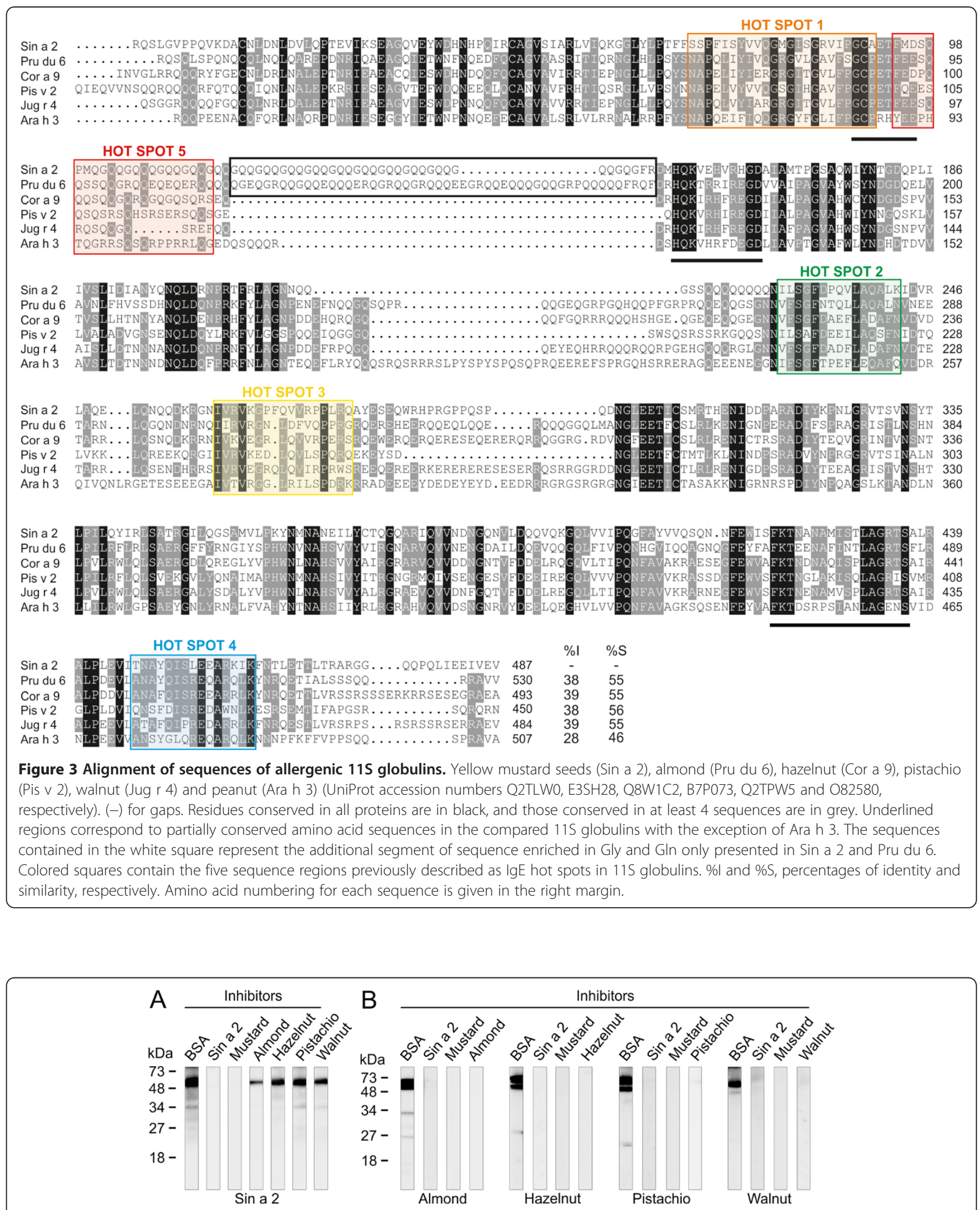

Figure 4 lgG-inhibition experiments in immunoblotting. Inhibition experiments of the lgG-binding of the rabbit anti-Sin a 2 serum (1/100000 diluted) to A) Sin a 2 and B) almond, hazelnut, pistachio and walnut protein extracts (50 $\mu \mathrm{g}$ of total protein per lane). BSA (20 $\mu \mathrm{g} / \mathrm{ml})$, Sin a $2(20 \mu \mathrm{g} / \mathrm{ml})$, mustard, hazelnut, pistachio or walnut protein extracts $(1 \mathrm{mg} / \mathrm{ml})$ were used as inhibitors. Molecular mass markers are displayed in the left margin. 

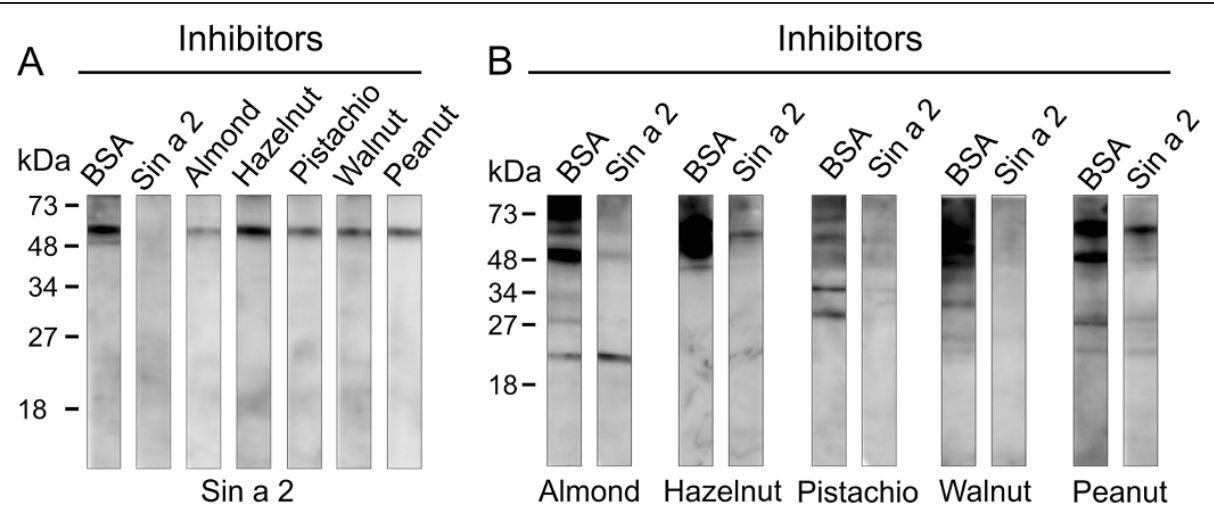

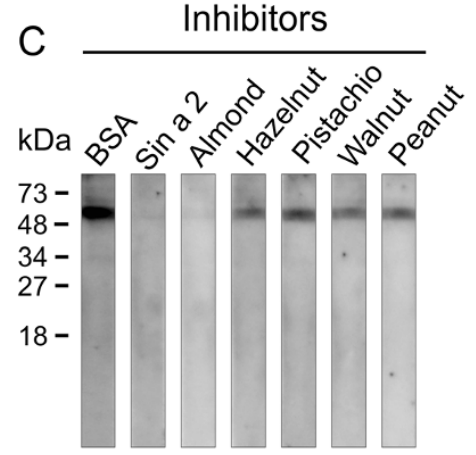

Sin a 2

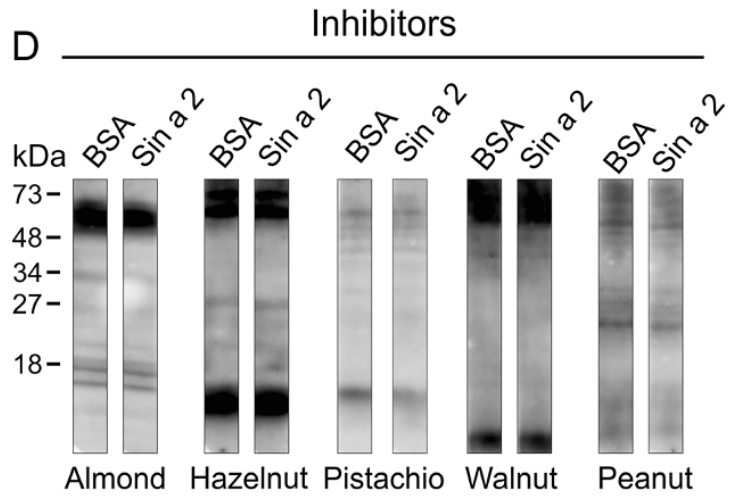

E Inhibitors

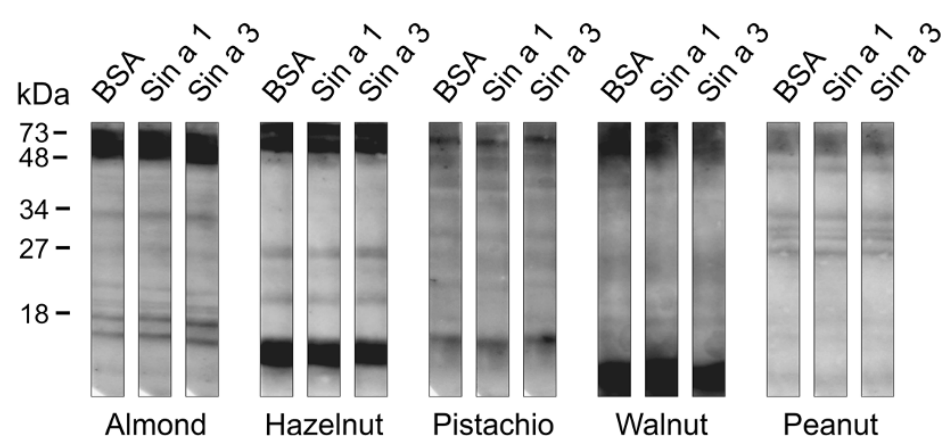

Figure 5 IgE-inhibition experiments in immunobloting. A) Inhibition of the IgE-binding to purified Sin a 2 of the pool of sera (1/5 diluted) from the group 1 of patients using as inhibitors BSA $(20 \mu \mathrm{g} / \mathrm{ml})$, Sin a $2(20 \mu \mathrm{g} / \mathrm{ml})$, almond, hazelnut, pistachio, walnut and peanut protein extracts $(1 \mathrm{mg} / \mathrm{ml})$. B) Inhibition of IgE-binding to almond, hazelnut, pistachio, walnut and peanut extracts (50 $\mu \mathrm{g}$ of total protein per lane) of the pool of sera from group 1 ( $1 / 5$ diluted) using as inhibitors BSA (control) or purified Sin a $2(20 \mu \mathrm{g} / \mathrm{ml})$. C, D and E) The same type of IgE-inhibition experiments using the pool of sera from the group 2 of patients and the indicated inhibitors. Molecular mass markers are displayed in the left margin.

by almond, hazelnut, pistachio, walnut and peanut $(83 \%, 62 \%, 60 \%, 67 \%, 69 \%$ and $67 \%$ of inhibition, respectively, as determined by scanning densitometry). This result firmly confirms that Sin a 2 share common IgE epitopes with allergenic $11 \mathrm{~S}$ globulins from tree nuts and peanuts. This pool of sera (group 2) also recognized IgE-reactive protein bands at around $48-52 \mathrm{kDa}$ that were not inhibited by Sin a 2 except in the case of almond (20\% of inhibition by scanning densitometry) (Figure 5D). These results together with the fact that the inhibition of the IgE-binding to purified Sin a 2 by tree nut and peanut extracts was considerably higher for group 2 than group 1 indicated that mustard allergic patients sensitized to Sin a 2 and allergic to tree nuts and/or peanut might well be also primarily co-sensitized to $11 \mathrm{~S}$ globulins from such allergenic sources. In 
addition, the pool of sera from group 2 recognized different low-molecular weight IgE-reactive protein bands $(<18 \mathrm{kDa})$ or epitopes from digested food that are not present in patient group 1 (Figure 5D and E), which could make the difference in the clinical symptoms associated with tree nuts and/or peanut ingestion. Interestingly, these IgE-reactive bands were not inhibited by $2 \mathrm{~S}$ albumin Sin a 1 nor LTP Sin a 3 (Figure 5E), indicating that these families of allergenic proteins are not involved in the observed cross-reactivity. Collectively, our data suggest that $\operatorname{Sin}$ a 2 and the homologous allergenic $11 \mathrm{~S}$ globulins from the studied tree nuts and peanut might contain both conserved cross-reactive and speciesspecific IgE epitopes. At this regard, several studies have previously shown the existence of five regions containing IgE-binding HS on $11 \mathrm{~S}$ globulins from tree nuts (almond, hazelnut, cashew or walnut), peanut and soybean $[19,33]$. Figures 3 and 6 show the amino acid sequence alignment of such regions comparing Sin a 2, Pru du 6, Cor a 9, Pis v 2, Jug r 4 and Ara $h 3$ as well as the location of the five IgE-binding HS on the 3D modelling of Sin a 2 and on the $3 D$ structure of Ara $h 3$. As shown in Figure 6A, the previously proposed IgE-binding HS-2 and HS-4 are quite conserved among the compared allergenic 11S globulins with percentages of identity with respect to Sin a 2 ranging from 40\% (Pis v 2 and Ara h 3 in HS-4) to 66\% (Pru du 6 and Cor a 9 in HS-4). The percentage of similarity with respect to $\operatorname{Sin}$ a 2 was even significantly higher and ranged from $66 \%$ (Jug $\mathrm{r} 4$ in HS2 and Pis $\mathrm{v} 2$ in HS-4) to $86 \%$ (Pru du 6 in HS-2 and Pru du 6 and Cor a 9 in HS-4). As visualized in the 3D modelling of Sin a 2 and in the 3D structure of Ara h 3, both HS-2 and HS-4 are located at solvent-exposed areas of the monomer, thus representing ideal potential IgE cross-reactive epitopes in allergenic $11 \mathrm{~S}$ globulins. When comparing HS-1, HS-3 and HS-5 lower percentages of identity were observed, being the HS- 5 the most dissimilar. In addition, HS-1, HS-3 and HS-5 were not completely solvent-exposed on the 3D modelling of Sin a 2 or on the $3 \mathrm{D}$ structure of Ara h 3 suggesting that they might well constitute potential species-specific IgE epitopes. The identification of clinically relevant IgE binding sites to which patients are sensitized will contribute to improve diagnosis and accurate endotyping, which might well subsequently lead to develop more efficient and safer patient-tailored immunotherapy approaches [46-48]. Altogether, our study indicates that mustard allergic patients sensitized to Sin a 2 could present positive SPT to tree nuts and/or peanut without clinical manifestations against these allergenic sources due to IgE cross-reactivity involving $11 \mathrm{~S}$ globulins. This finding is especially significant as it could help to avoid wrong diagnosis due to IgE cross-reactivity without clinical relevance. The fact that we also demonstrated IgE cross-reactivity involving Sin a 2 in mustard allergic patients sensitized to this allergen with clinical symptoms to tree nuts and/or peanut suggests the possibility that patients sensitized to Sin a 2 might eventually develop clinical episodes against these allergenic sources. Although the clinical relevance of the cross-reactive IgEbinding sites of the $11 \mathrm{~S}$ globulin $\operatorname{Sin}$ a 2 needs to be studied in further detail, our results contribute to

\begin{tabular}{ccccccccccc}
\multirow{2}{*}{ A } & \multicolumn{3}{c}{ Hot Spot 1 } & \multicolumn{2}{c}{ Hot Spot 2 } & \multicolumn{2}{c}{ Hot Spot 3 } & \multicolumn{2}{c}{ Hot Spot 4 } & \multicolumn{2}{c}{ Hot Spot 5 } \\
& $\%$ I & $\%$ S & $\%$ I & $\%$ S & $\%$ I & $\%$ S & $\%$ I & $\%$ S & \% I & $\%$ S \\
\hline Sin a 2 & - & - & - & - & - & - & - & - & - & - \\
\hline Pru du 6 & 43 & 65 & 60 & 86 & 41 & 64 & 66 & 86 & 34 & 56 \\
\hline Cor a 9 & 39 & 69 & 46 & 73 & 52 & 70 & 66 & 86 & 47 & 52 \\
\hline Pis v 2 & 56 & 69 & 53 & 80 & 47 & 64 & 40 & 66 & 18 & 36 \\
\hline Jug r 4 & 39 & 69 & 46 & 66 & 50 & 66 & 46 & 73 & 31 & 40 \\
\hline Ara h 3 & 34 & 56 & 53 & 80 & 29 & 64 & 40 & 73 & 17 & 43 \\
\hline
\end{tabular}

B
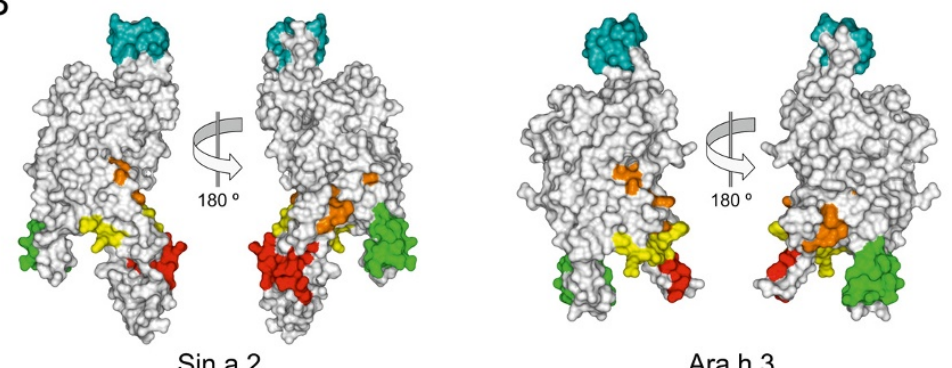

Ara h 3

Figure 6 Comparison of the lgE-binding hot spots among allergenic $11 \mathrm{~S}$ globulins and localization on the 3D structure of Sin a 2 and Ara h 3. A) Table showing the percentage of identity (\% I) and similarity (\% S) of the five lgE hot spots described in $11 \mathrm{~S}$ globulins from almond (Pru du 6), hazelnut (Cor a 9), pistachio (Pis $\vee$ 2), walnut (Jug $r$ 4) and peanut (Ara h 3) with respect to mustard (Sin a 2). B) Location of the lgE hot spots on the molecular surface of the modelled 3D structure of $\operatorname{Sin}$ a 2 and on the 3D structure of Ara $\mathrm{h} 3$. Hot spot regions on the 3D structures are colored in orange (hot spot 1), green (hot spot 2), yellow (hot spot 3), blue (hot spot 4) or red (hot spot 5). 
improve the diagnosis and management of the patients allergic to mustard sensitized to this allergen.

\section{Conclusions}

In this study we demonstrated at the molecular level that the $11 \mathrm{~S}$ globulin Sin a 2, which is associated with severe reactions in mustard allergic patients, is involved in cross-reactivity among mustard, tree nuts and peanut. Sin a 2 shares IgG epitopes with allergenic $11 \mathrm{~S}$ globulins from tree nuts (almond, hazelnut, pistachio and walnut) but not with peanut. At the IgE level, we showed that $11 \mathrm{~S}$ globulins contain conserved IgE epitopes involved in cross-reactivity among mustard, tree nuts and peanut as well as specie-specific IgE epitopes. Due to the severity of symptoms associated to Sin a 2, the definitive demonstration of the clinical relevance and the involvement of the IgE cross-reactive epitopes of $11 \mathrm{~S}$ globulins in triggering symptoms is an important issue that will require in depth clinical studies in future.

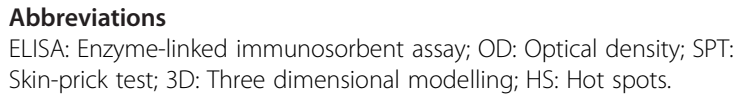

\section{Competing interests}

The authors declare that they do not have competing interests.

\section{Authors' contributions}

Conceived and designed the experiments: OP and SS. Performed the in vitro experiments: SS and MA. Clinical characterization of the patients: AV and JCH. Analysed and discussed the data: OP, SS, JCH, MV and RR. Contributed reagents/materials/analysis tools: $\mathrm{AV}, \mathrm{JCH}, \mathrm{OP}, \mathrm{RR}$ and $\mathrm{MV}$. Wrote the paper: OP. All the authors read and approved the final manuscript.

\section{Acknowledgements}

The authors' laboratories are supported by grants SAF2011-26716 from MINECO (Ministerio de Economía y Competitividad) and RD07/0064/0009 from FIS (Fondo de Investigación Sanitaria). O.P. is a Ramon y Cajal Scholar funded by MINECO and the European Social Fund.

\section{Author details}

'Department of Biochemistry and Molecular Biology, School of Chemistry, Complutense University of Madrid, Madrid 28040, Spain. ${ }^{2}$ Service of Allergy, IIS-Fundación Jiménez Díaz, Madrid, Spain.

Received: 1 October 2012 Accepted: 7 December 2012

Published: 11 December 2012

\section{References}

1. Burks AW, Tang M, Sicherer S, Muraro A, Eigenmann PA, Ebisawa M, Fiocchi A, Chiang W, Beyer K, Wood R, et al: ICON: food allergy. J Allergy Clin Immunol 2012, 129:906-920.

2. Chafen JJ, Newberry SJ, Riedl MA, Bravata DM, Maglione M, Suttorp MJ, Sundaram V, Paige NM, Towfigh A, Hulley BJ, Shekelle PG: Diagnosing and managing common food allergies: a systematic review. JAMA 2010, 303:1848-1856.

3. Akiyama $H$, Imai T, Ebisawa M: Japan food allergen labeling regulationhistory and evaluation. Adv Food Nutr Res 2011, 62:139-171.

4. Monreal P, Botey J, Pena M, Marin A, Eseverri JL: Mustard allergy. Two anaphylactic reactions to ingestion of mustard sauce. Ann Allergy 1992, 69:317-320.

5. Panconesi E, Sertoli A, Fabbri P, Giorgini S, Spallanzani P: Anaphylactic shock from mustard after ingestion of pizza. Contact Dermatitis 1980, 6:294-295.
6. Stricker WE, Anorve-Lopez E, Reed CE: Food skin testing in patients with idiopathic anaphylaxis. J Allergy Clin Immunol 1986, 77:516-519.

7. Widstrom L, Johansson SG: IgE-mediated anaphylaxis to mustard. Acta Derm Venereol 1986, 66:70-71.

8. Kanny G, Fremont S, Talhouarne G, Nicolas JP, Moneret-Vautrin DA: Anaphylaxis to mustard as a masked allergen in "chicken dips". Ann Allergy Asthma Immunol 1995, 75:340-342.

9. Directive 2006/142/EC of the European Parlament and of the Council of 29 Novemer 2006, amending directive 2000/13/EC. available at http://ec.europa. eu/food/labellingnutrition/foodlabelling/proposed_legislation_en.htm.

10. Menendez-Arias L, Moneo I, Dominguez J, Rodriguez R: Primary structure of the major allergen of yellow mustard (Sinapis alba L.) seed, Sin a I. Eur J Biochem 1988, 177:159-166.

11. Palomares $\mathrm{O}$, Cuesta-Herranz J, Rodriguez R, Villalba M: A recombinant precursor of the mustard allergen Sin a 1 retains the biochemical and immunological features of the heterodimeric native protein. Int Arch Allergy Immunol 2005, 137:18-26.

12. Palomares O, Cuesta-Herranz J, Vereda A, Sirvent S, Villalba M, Rodriguez R: Isolation and identification of an $11 \mathrm{~S}$ globulin as a new major allergen in mustard seeds. Ann Allergy Asthma Immunol 2005, 94:586-592.

13. Palomares O, Vereda A, Cuesta-Herranz J, Villalba M, Rodriguez R: Cloning, sequencing, and recombinant production of $\operatorname{Sin}$ a 2 , an allergenic $11 \mathrm{~S}$ globulin from yellow mustard seeds. J Allergy Clin Immunol 2007, 119:1189-1196.

14. Sirvent S, Palomares O, Vereda A, Villalba M, Cuesta-Herranz J, Rodriguez R: nsLTP and profilin are allergens in mustard seeds: cloning, sequencing and recombinant production of Sin a 3 and Sin a 4. Clin Exp Allergy 2009, 39:1929-1936.

15. Sirvent S, Palomares O, Cuesta-Herranz J, Villalba M, Rodriguez R: Analysis of the Structural and Immunological Stability of $2 S$ Albumin, Nonspecific Lipid Transfer Protein, and Profilin Allergens from Mustard Seeds. J Agric Food Chem 2012, 60:6011-6018.

16. Vereda A, Sirvent S, Villalba M, Rodriguez R, Cuesta-Herranz J, Palomares O: Improvement of mustard (Sinapis alba) allergy diagnosis and management by linking clinical features and component-resolved approaches. J Allergy Clin Immunol 2011, 127:1304-1307.

17. Caballero T, San-Martin MS, Padial MA, Contreras J, Cabanas R, Barranco P, Lopez-Serrano MC: Clinical characteristics of patients with mustard hypersensitivity. Ann Allergy Asthma Immunol 2002, 89:166-171.

18. Figueroa J, Blanco C, Dumpierrez AG, Almeida L, Ortega N, Castillo R, Navarro L, Perez E, Gallego MD, Carrillo T: Mustard allergy confirmed by double-blind placebo-controlled food challenges: clinical features and cross-reactivity with mugwort pollen and plant-derived foods. Allergy 2005, 60:48-55.

19. Willison LN, Tripathi P, Sharma G, Teuber SS, Sathe SK, Roux KH: Cloning, expression and patient lgE reactivity of recombinant Pru du 6, an 11S globulin from almond. Int Arch Allergy Immunol 2011, 156:267-281.

20. Beyer K, Grishina G, Bardina L, Grishin A, Sampson HA: Identification of an $11 \mathrm{~S}$ globulin as a major hazelnut food allergen in hazelnut-induced systemic reactions. J Allergy Clin Immunol 2002, 110:517-523.

21. Verweij MM, Hagendorens MM, De Knop KJ, Bridts CH, De Clerck LS, Stevens WJ, Ebo DG: Young infants with atopic dermatitis can display sensitization to Cor a 9, an 11S legumin-like seed-storage protein from hazelnut (Corylus avellana). Pediatr Allergy Immunol 2011, 22:196-201.

22. Koppelman SJ, Knol EF, Vlooswijk RA, Wensing M, Knulst AC, Hefle SL, Gruppen $\mathrm{H}$, Piersma S: Peanut allergen Ara $\mathrm{h}$ 3: isolation from peanuts and biochemical characterization. Allergy 2003, 58:1144-1151.

23. Wallowitz M, Peterson WR, Uratsu S, Comstock SS, Dandekar AM, Teuber SS: Jug $r$, a legumin group food allergen from walnut (Juglans regia Cv. Chandler). J Agric Food Chem 2006, 54:8369-8375.

24. Ahn K, Bardina L, Grishina G, Beyer K, Sampson HA: Identification of two pistachio allergens, Pis v 1 and Pis $\vee 2$, belonging to the $2 S$ albumin and 11S globulin family. Clin Exp Allergy 2009, 39:926-934.

25. Helm RM, Cockrell G, Connaughton C, Sampson HA, Bannon GA, Beilinson V, Nielsen NC, Burks AW: A soybean G2 glycinin allergen. 2. Epitope mapping and three-dimensional modeling. Int Arch Allergy Immunol 2000, 123:213-219. 
26. Pastorello EA, Farioli L, Pravettoni V, Ispano M, Conti A, Ansaloni R, Rotondo F, Incorvaia C, Bengtsson A, Rivolta F, et al: Sensitization to the major allergen of Brazil nut is correlated with the clinical expression of allergy. J Allergy Clin Immunol 1998, 102:1021-1027.

27. Teuber SS, Sathe SK, Peterson WR, Roux KH: Characterization of the soluble allergenic proteins of cashew nut (Anacardium occidentale L.). J Agric Food Chem 2002, 50:6543-6549.

28. Wallowitz ML, Chen RJ, Tzen JT, Teuber SS: Ses i 6, the sesame 11S globulin, can activate basophils and shows cross-reactivity with walnut in vitro. Clin Exp Allergy 2007, 37:929-938.

29. Sharma GM, Irsigler A, Dhanarajan P, Ayuso R, Bardina L, Sampson HA, Roux $\mathrm{KH}$, Sathe SK: Cloning and characterization of an 11S legumin, Car i 4, a major allergen in pecan. J Agric Food Chem 2011, 59:9542-9552.

30. Manso L, Pastor C, Perez-Gordo M, Cases B, Sastre J, Cuesta-Herranz J: Cross-reactivity between coconut and lentil related to a $7 \mathrm{~S}$ globulin and an $11 S$ globulin. Allergy 2010, 65:1487-1488

31. Varga EM, Kollmann D, Zach M, Bohle B: Anaphylaxis to buckwheat in an atopic child: a risk factor for severe allergy to nuts and seeds? Int Arch Allergy Immunol 2011, 156:112-116.

32. Ballabio C, Magni C, Restani P, Mottini M, Fiocchi A, Tedeschi G, Duranti M: IgE-mediated cross-reactivity among leguminous seed proteins in peanut allergic children. Plant Foods Hum Nutr 2010, 65:396-402.

33. Robotham JM, Hoffman GG, Teuber SS, Beyer K, Sampson HA, Sathe SK, Roux KH: Linear IgE-epitope mapping and comparative structural homology modeling of hazelnut and English walnut 11S globulins. $\mathrm{Mol}$ Immunol 2009, 46:2975-2984.

34. Guo F, Kothary MH, Wang Y, Yu X, Howard AJ, Fu TJ, Zhang YZ: Purification and crystallization of Cor a 9, a major hazelnut allergen. Acta Crystallogr Sect F Struct Biol Cryst Commun 2009, 65:42-46.

35. Comité de reacciones adversas a alimentos: Sociedad Española de Alergología e Inmunología Clínica. Metodología diagnóstica en la alergia a alimentos. Alergol Inmunol Clin 1999, 14:50-62

36. Malling HJ: Skin prick testing in biological standardization of allergenic products. Arb Paul Ehrlich Inst Bundesamt Sera Impfstoffe Frankf AM 1997, 91:157-163.

37. Dreborg S: Skin testing. The safety of skin tests and the information obtained from using different methods and concentrations of allergen. Allergy 1993, 48:473-475.

38. Palomares $\mathrm{O}$, Monsalve Rl, Rodriguez R, Villalba M: Recombinant pronapin precursor produced in Pichia pastoris displays structural and immunologic equivalent properties to its mature product isolated from rapeseed. Eur J Biochem 2002, 269:2538-2545.

39. Sievers F, Wilm A, Dineen D, Gibson TJ, Karplus K, Li W, Lopez R, McWilliam $H$, Remmert M, Soding J, et al: Fast, scalable generation of high-quality protein multiple sequence alignments using Clustal Omega. Mol Syst Biol 2011, 7:539.

40. Petersen TN, Brunak S, von Heijne G, Nielsen H: SignalP 4.0: discriminating signal peptides from transmembrane regions. Nat Methods 2011, 8:785-786.

41. Bordoli L, Kiefer F, Arnold K, Benkert P, Battey J, Schwede T: Protein structure homology modeling using SWISS-MODEL workspace. Nat Protoc 2009, 4:1-13.

42. Adachi M, Kanamori J, Masuda T, Yagasaki K, Kitamura K, Mikami B, Utsumi S: Crystal structure of soybean 11S globulin: glycinin A3B4 homohexamer. Proc Natl Acad Sci USA 2003, 100:7395-7400.

43. Palomares O, Alcantara M, Quiralte J, Villalba M, Garzon F, Rodriguez R: Airway disease and thaumatin-like protein in an olive-oil mill worker. N Engl J Med 2008, 358:1306-1308.

44. Valenta R, Twaroch T, Swoboda I: Component-resolved diagnosis to optimize allergen-specific immunotherapy in the Mediterranean area. J Investig Allergol Clin Immunol 2007, 17(Suppl 1):36-40.

45. Palomares O, Villalba M, Quiralte J, Polo F, Rodriguez R: 1,3-beta-glucanases as candidates in latex-pollen-vegetable food cross-reactivity. Clin Exp Allergy 2005, 35:345-351.

46. Bogh KL, Nielsen H, Madsen CB, Mills EN, Rigby N, Eiwegger T, Szepfalusi Z, Roggen EL: IgE epitopes of intact and digested Ara h 1: a comparative study in humans and rats. Mol Immunol 2012 51:337-346
47. Calderon MA, Demoly P, van Gerth Wijk R, Bousquet J, Sheikh A, Frew A, Scadding G, Bachert C, Malling HJ, Valenta R, et al: EAACl: A European Declaration on Immunotherapy. Designing the future of allergen specific immunotherapy. Clin Transl Allergy 2012, 2:20.

48. Papadopoulos NG, Agache I, Bavbek S, Bilo BM, Braido F, Cardona V, Custovic A, Demonchy J, Demoly P, Eigenmann $P$, et al: Research needs in allergy: an EAACI position paper, in collaboration with EFA. Clin Trans/ Allergy 2012, 2:21.

doi:10.1186/2045-7022-2-23

Cite this article as: Sirvent et al: The $11 \mathrm{~S}$ globulin Sin a 2 from yellow mustard seeds shows IgE cross-reactivity with homologous counterparts from tree nuts and peanut. Clinical and Translational Allergy 2012 2:23.

\section{Submit your next manuscript to BioMed Central and take full advantage of:}

- Convenient online submission

- Thorough peer review

- No space constraints or color figure charges

- Immediate publication on acceptance

- Inclusion in PubMed, CAS, Scopus and Google Scholar

- Research which is freely available for redistribution 